\title{
Evaluation of hydrothermal carbonization in urban mining for the recovery of phosphorus from the organic fraction of municipal solid waste
}

\author{
Oliver-Tomas, Borja; Hitzl, Martin; Owsianiak, Mikoaj; Renz, Michael
}

Published in:

Resources, Conservation and Recycling

Link to article, DOI:

10.1016/j.resconrec.2019.04.023

Publication date:

2019

Document Version

Peer reviewed version

Link back to DTU Orbit

Citation (APA):

Oliver-Tomas, B., Hitzl, M., Owsianiak, M., \& Renz, M. (2019). Evaluation of hydrothermal carbonization in urban mining for the recovery of phosphorus from the organic fraction of municipal solid waste. Resources, Conservation and Recycling, 147, 111-118. https://doi.org/10.1016/j.resconrec.2019.04.023

\section{General rights}

Copyright and moral rights for the publications made accessible in the public portal are retained by the authors and/or other copyright owners and it is a condition of accessing publications that users recognise and abide by the legal requirements associated with these rights.

- Users may download and print one copy of any publication from the public portal for the purpose of private study or research.

- You may not further distribute the material or use it for any profit-making activity or commercial gain

- You may freely distribute the URL identifying the publication in the public portal 
1 Oliver-Tomas, B., Hitzl, M., Owsianiak, M., \& Renz, M. (2019). Evaluation of

2 hydrothermal carbonization in urban mining for the recovery of phosphorus from

3 the organic fraction of municipal solid waste. Resources, Conservation and

4 Recycling, 147, 111-118. https://doi.org/10.1016/j.resconrec.2019.04.023

5 
6 Evaluation of hydrothermal carbonization in urban mining for the

7 recovery of phosphorus from the organic fraction of municipal

8 solid waste

9

Borja Oliver-Tomas, ${ }^{\mathrm{a}, \mathrm{c}}$ Martin Hitzl, ${ }^{\mathrm{a}}$ Mikołaj Owsianiak, ${ }^{\mathrm{b}}$ Michael Renz ${ }^{* c}$

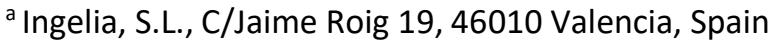

${ }^{\mathrm{b}}$ Division for Quantitative Sustainability Assessment, Department of Management Engineering, Technical University of Denmark, Bygningstorvet, Building 116B, DK-2800 Kgs. Lyngby, Denmark

c Instituto de Tecnología Química (UPV-CSIC), Universitat Politècnica de València - Consejo Superior de Investigaciones Científicas, Avenida de los Naranjos s/n, 46022 Valencia, Spain; Email:mrenz@itq.upv.es

\section{Abstract}

The organic fraction of municipal solid waste was identified as an alternative phosphorus resource: hydrothermal carbonization provided phosphorus-rich hydrochar. Two alternative valorization pathways can be considered for the latter: the use as a fertilizer or as solid fuel after phosphorus extraction. By means of life cycle assessment (LCA) the environmental impact of extracting phosphorus and using the hydrochar as solid fuel was evaluated. Therefore, in a first step, phosphorus extraction with nitric acid, hydrochloric acid and sulfuric acid was experimentally investigated on laboratory scale. Nitric acid proved to be the most suitable because it offered high extraction efficiency and improved solid fuel properties such as lower ash content and lower levels of chlorine and sulfur. In contrast, hydrochloric acid increased the chlorine content and sulfuric acid only replaced phosphate by sulfate, but did not reduce the ash content of hydrochar. Then phosphorus can be precipitated and used as fertilizer.

Although technically feasible, LCA points out that the separate use of hydrochar and phosphorus represents an overall environmental burden for wide range of impact categories, including climate change and resource depletion. Therefore, other applications for phosphorus-rich hydrochars, like agriculture and horticulture, should be considered.

Advanced hydrochar, low-ash solid fuel, phosphorus extraction, phosphorus fertilizer, 
42

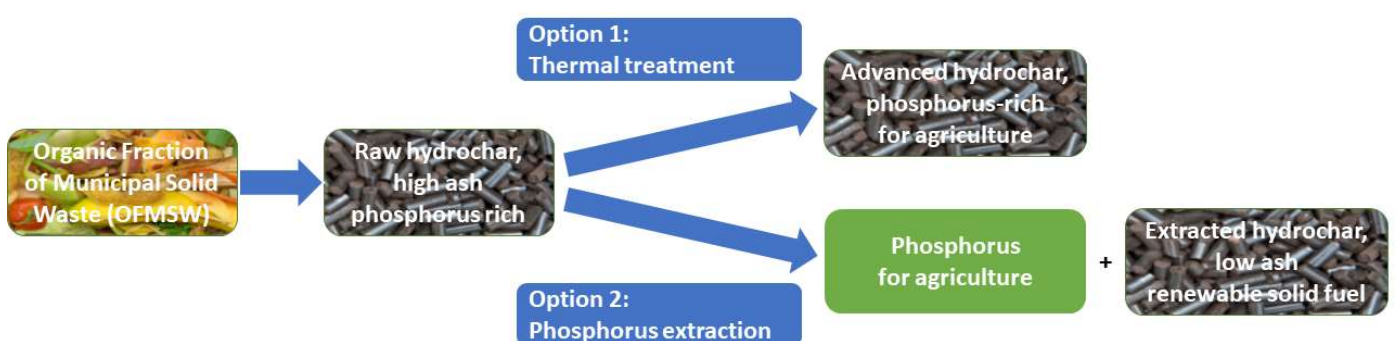

43 
Introduction

Phosphorus is an essential element for all life on earth, and the European Commission (EC) has identified phosphate rock as a critical raw material in 2017 with a nonexistent recycling rate.(European Commission, 2017) Approximately 95\% of the world's phosphate production is used in the fertilizer industry.(Desmidt et al., 2015) This figure makes it clear that phosphate consumption is strongly related to nutrition and population growth.

Phosphorus is a chemical element whose use does not make it disappear, but spreads it out on the planet. Therefore, the recovery of phosphorus from alternative sources is urgently needed. A promising approach is to perform a fixation step for the phosphorus, a type of homogenization and concentration. For example, sewage sludge is a plant nutrient rich resource(Zhang et al., 2018, 2017) and when sewage sludge is incinerated, phosphorus is concentrated in the ash and the liquid phase is then absent.(Cieślik and Konieczka, 2017; Melia et al., 2017) The ashes can directly be used as fertilizers but phosphorus extraction with mineral acid and precipitation increases its bioavailability.(Cieślik and Konieczka, 2017)

The present study was initiated when elevated phosphorus concentrations were determined for hydrochar originating from the organic fraction of municipal solid waste (OFMSW). It became evident that hydrothermal carbonization (HTC) can be part of a novel process for phosphorus concentration from this undervalorized resource. The HTC process is an emerging technology and produces hydrochar, a solid carbonaceous material, as main product from wet lignocellulosic biomass such as the OFMSW.(Funke and Ziegler, 2010; Hu et al., 2010; Titirici et al., 2012; Maria M Titirici et al., 2007) The wet conditions during the process make the previous drying superfluous, which is a significant advantage over alternative thermochemical processes (torrefaction, pyrolysis, and gasification), considering the economics for wet feedstocks.(Cha et al., 2016; Kambo and Dutta, 2015)

In terms of valorization and commercialization of phosphorous-containing hydrochar, two main pathways can compete with each other: application of phosphorus-containing hydrochar to soil(Lang et al., 2019) or phosphorus extraction for its use in agriculture and the use of the depleted hydrochar as solid fuel.

For the use of hydrochar in agriculture, a post-treatment is required as pristine hydrochar may involve phytotoxicity. Therefore, several options are known(Busch et al., 2013, 2012; Dalias et al., 2018; Fornes and Belda, 2017) and a by-product-free treatment is to desorb the undesired compounds and to use them directly for heat generation for the HTC process.(Hitzl et al., 2018) In the latter case, the product is referred to as advanced hydrochar, which is suitable for agriculture, to distinguish it clearly from pristine hydrochar. The use of pristine hydrochar in agriculture, e.g. in Spain, involves climate change benefits,(Owsianiak et al., 2018) and a rough estimation confirmed that this also applies to advanced hydrochars.(Hitzl et al., 2018)

When hydrochar is considered a solid fuel and phosphorus should be destined to agriculture, then phosphorus should be extracted at the production site and, thereby, further concentrated. The reason for this is that burning of hydrochar as solid fuel is foreseen in smaller units such as domestic or district heating systems. This leads again to a territorial spread of the phosphorus-rich ash, which would cause again logistic costs for its collection.

An additional economic benefit of this approach is the improvement in the fuel quality of hydrochar.(Wang et al., 2018) Phosphorus forms part of the ashes of hydrochar, and its removal reduces the ash content. This is relevant because carbonaceous materials are classified as solid fuels in terms of their ash content.(International Organization for 
Standardization, n.d.) Improving the product quality of hydrochar as a solid fuel increases its value and contributes positively to the economic balance of the production process.

Here we show that the phosphorus extraction from hydrochar is generally possible with mineral acid. By simply neutralizing the extract, phosphorus is recovered and can then be marketed as a solid fertilizer from secondary phosphate sources. Based on these data, we performed the Life Cycle Assessment (LCA) of the developed process, considering the extracted hydrochar as solid fuel and the consequences of its combustion.

\section{Materials and Methods}

\section{Hydrothermal carbonization}

All residual biomass was processed at Ingelia's pilot plant.(Hitzl et al., 2015) The production of hydrochar from the OFMSW has been described elsewhere.(Hitzl et al., 2018) The organic fraction was obtained from households in Guipúzcoa (The Basque Country, Spain) by separate collection which was operated by Gipuzkoako Hondakinen Kudeaketa SAU. It contained biodegradable plastic bags, glass and plastic bottles as "impurities" in low amount and a water content of $75 \%$. For the trial, $9.24 \mathrm{t}$ of this resource were transformed into $1.05 \mathrm{t}$ of dry hydrochar with an ash content of $12.9 \%$ (determined by calcination at $815^{\circ} \mathrm{C}$ ).(Hitzl et al., 2018) Details on the processing of green waste can be found in literature,(Hitzl et al., 2015) as well as for the transformation of orange peel waste (OPW).(Burguete et al., 2016) Hydrochar from sewage sludge was also produced at Ingelia's pilot plant during the FP7 NEWAPP project.(“New technological applications for wet biomass waste stream products," n.d.)

\section{Phosphorus extraction}

In a round-bottom flask, $4.00 \mathrm{~g}$ of hydrochar was placed together with $15 \mathrm{~mL}$ of acid solution. The latter was prepared from HTC process water obtained from Ingelia, adding the amount of the corresponding concentrated acid to reach the desired concentration. The final concentration of sulfuric acid was $5 \mathrm{wt} \%$, of nitric acid $6 \mathrm{wt} \%$, and of hydrochloric acid $4-5$ $w t \%$. During the acidification of the process water, a solid precipitated which was removed by filtration and discarded. The hydrochar suspension was stirred for four hours at different temperatures, namely at $40,60,80$, and $100^{\circ} \mathrm{C}$ (see also, Figure S2, ESI). The solid was collected by filtration, washed with $100 \mathrm{~mL}$ of deionized water and dried overnight at $100{ }^{\circ} \mathrm{C}$. Phosphorus content in hydrochar was calculated from ash content and ash composition, the latter determined by inductively coupled plasma optical emission spectrometry (ICP-OES) on a Varian 715 ES spectrometer. Phosphorus recovered was calculated from the amounts and concentrations of the acid extract and the washing water. Their phosphorus content was determined directly by ICP-OES. Higher heating values (HHV) were determined following the analytical standard UNE-EN 14918:2011.

\section{Phosphorus precipitation}

For phosphorus precipitation the $\mathrm{pH}$ of the acid extract was adjusted to 8 to 9.5 adding calcium hydroxide. The solid was collected by filtration and dried in an oven at $100{ }^{\circ} \mathrm{C}$ overnight.

\section{LCA modelling part}

Environmental performance of phosphorus removal was assessed using environmental LCA. It was conducted in accordance with the requirements of the ISO 14044 standard and the guidelines of the EU Commission's International Reference Life Cycle Data System (ILCD) Handbook. (ILCD Handbook: General guide for Life Cycle Assessment - Detailed guidance, 2010, 
ISO 14044:2006 Environmental management -- Life cycle assessment -- Requirements and guidelines, 2006)

\section{Goal and scope}

Because hydrothermal carbonization is a waste treatment option, the functional unit was defined as "hydrothermal carbonization of $1 \mathrm{~kg}$ of wet biowaste with $100 \%$ content of biogenic carbon of total carbon". This definition allows for a fair comparison between biowaste with varying phosphorus content and with hydrothermal carbonization of biowaste without phosphorus recovery. The most likely use of hydrochar is as solid fuel for domestic heating. Nitrogen and sulfur content of the hydrochar were taken into account for emissions, whereas a complete elimination of the mineral acids during the washing process was assumed.

The current study is considered a micro-level decision support (type A) situation according to ILCD guidelines, and the assessment applies an attributional approach where average Spanish data are used. System boundaries specifying the processes included have been described before.(Owsianiak et al., 2016) We included replaced the conventional waste management system (composting), replaced combustion of fossil coal, construction of a HTC plant, production of the hydrochar and HTC process water and transportation of the hydrochar. In addition, production of acids and base for recovery of $\mathrm{P}$ was included. System expansion was performed for processes with recovery of commodities; recycled steel substitutes the production of virgin steel and the HTC process water (concentrated at the HTC plant using reverse osmosis) substitutes the production of inorganic fertilizers. Likewise, impact offsets (also known as credits) are given to recovered phosphorus (replacing phosphorus from phosphate rock), to avoided conventional treatment of biowaste, and to energy recovery when hydrochar is used for domestic heating (replacing combustion of fossil coal), in accordance with the recommendations of the ILCD guidelines for this decision support type.

Product systems were modelled in SimaPro, version 8.3.0.0 (PRe Consultants bv, the Netherlands). Parameters and data underlying the modeling of HTC plant are documented in literature.(Owsianiak et al., 2016) Data for foreground processes in the HTC system, are based on primary data measured at a HTC plant at Ingelia S.L. (Valencia, Spain). Data for generic processes, such as electricity production and waste management processes, are based on those available in the ecoinvent database, version 3.2.(Weidema et al., 2013)

ILCD's method was used in the life cycle impact assessment phase (ILCD 2011 Midpoint+, version 1.05),(Hauschild et al., 2013) as implemented in the LCA modeling software SimaPro, version 8.3.0.0 (PRe Consultants bv, the Netherlands). All ILCD impact categories were used, except ionizing radiation impacts on ecosystems which is considered not sufficiently representative for this type of impact.

\section{Scenarios}

In total, twelve scenarios were considered (Table 1$)$. Overall, three different acids $\left(\mathrm{HNO}_{3}\right.$, $\mathrm{H}_{2} \mathrm{SO}_{4}$ and $\mathrm{HCl}$ ) in two concentrations applied to phosphorus extraction from hydrochar made from the OFMSW and a hypothetical one with the double phosphorus amount. In detail, for the first three scenarios (1-3) the same acid (and base) concentrations and amounts were used as in the experiments. Initial phosphorus content in the hydrochar for these scenarios was the content measured for hydrochar made from the OFMSW (1.25\%; $22.1 \%$ of the ashes), which is in a higher range than values measured for hydrochars made from other biowaste types. Assuming that amounts of acids and bases can be optimized during up-scaling, further three scenarios were considered with amounts of acids and base reduced 10 times (scenarios 
177 4-6). In addition, as starting material for the extractions, in six scenarios hydrochar was

178 considered to involve the double amount of phosphorus, compared to the current one.

179 Hereby, extraction efficiency was maintained. In the first group, acid amount was maintained

180 as in the experimental procedures (scenarios 7-9) and in the second group (scenarios 10-12)

181 reduced acid amounts and concentrations were used. Sensitivity of the results to the

182 parameters presented in Table 1 was done by simply comparing impact scores between

183 scenarios.

184

\begin{tabular}{lllll} 
Scenario & Sensitivity parameter & Acid type & Acid concentration & P content \\
\hline 1 & Baseline & $\mathrm{HNO}_{3}$ & High (6\%) & High (1.25\%) \\
2,3 & Acid type & $\mathrm{HCl} ; \mathrm{H}_{2} \mathrm{SO}_{4}$ & High (4\%; 6\%) & High (1.25\%) \\
$4-6$ & Acid concentration & $\mathrm{HNO}_{3} ; \mathrm{HCl} ; \mathrm{H}_{2} \mathrm{SO}_{4}$ & Optimized (1/10 of initial) & High (1.25\%) \\
$7-9$ & P content & $\mathrm{HNO}_{3} ; \mathrm{HCl} ; \mathrm{H}_{2} \mathrm{SO}_{4}$ & High (4\%; 6\%) & Very high (2.50\%) \\
$10-12$ & $\begin{array}{l}\text { All potential } \\
\text { improvements }\end{array}$ & $\mathrm{HNO}_{3} ; \mathrm{HCl} ; \mathrm{H}_{2} \mathrm{SO}_{4}$ & Optimized (1/10 of initial) & Very high (2.50\%) \\
\hline
\end{tabular}

185

186 Table 1. Overview of scenarios used in the scenario analysis.

187 
Results and discussion

Phosphorus extraction

As previously reported, the organic fraction of municipal solid waste has been converted into hydrochar on a ton scale.(Hitzl et al., 2018) In a nutshell, $9.24 \mathrm{t}$ of wet starting material gave $1.05 \mathrm{t}$ of dry hydrochar, which corresponded to a mass yield of $45 \%$ (based on dry matter). The total ash content of the hydrochar was $13 \%$ and the concentrations of its major components are shown in Figure S1. From these data a total phosphorus content in the hydrochar of $1.25 \%$ (as P) was calculated. This high concentration was relatively surprising as the phosphorus content was generally neglected in the analysis of hydrochar. When it was reported, it was significantly lower at $0.42 \%$ for food waste.(Idowu et al., 2017)

The second HTC product, the process water, generally contains a low phosphorus concentration of less than $5 \mathrm{ppm}$. Therefore, it can be concluded that phosphorus is fixed in hydrochar, i.e. all phosphorus present in the wet raw material is recovered in dry hydrochar and, its concentration is increased by a factor of nearly nine in the present case.

Nevertheless, the phosphorus concentration in the solid hydrochar was still an order of magnitude lower than in the phosphate rock, in which its concentration is typically between 13 and $17 \%$. However, hydrochar offers advantages over the rock for the extraction process. In particular, hydrochar already has a small particle size $(<5 \mathrm{~cm})$ and a high grindability index (the particle size is further reduced easily by milling).(Kempegowda et al., 2017; Smith et al., 2018) In addition, the chemical transformation during the HTC, that is, the dehydration, breaks up the plant structure(Hitzl et al., 2015) and the hard biomass is "perforated by a spongy, continuous system of nanopores".(M M Titirici et al., 2007) Therefore, it should be easy for an extracting liquid to completely penetrate the carbonaceous material and access all phosphorus domains.

With the aim to proof this hypothesis, the hydrochar derived from OFMSW was extracted with three different mineral acids, sulfuric acid, hydrochloric acid and nitric acid. In fact, Figure S2 shows that all three acids were able to remove the phosphorus almost quantitatively with an efficiency of more than $96 \%$. In addition, the extraction was independent of the reaction temperature: In the temperature range from $40^{\circ} \mathrm{C}$ to $100^{\circ} \mathrm{C}$, no significant change in the efficiency was observed. This is relevant because in the industrial HTC process a hot hydrochar water slurry exits the reactor and cools down during the downstream processing. The results of the extraction indicated that the temperature of the carbonaceous material could be neglected and the extraction could be carried out after excess process water had been removed in the filter press (to a humidity of approximately $50 \%$ ).

Phosphorus extraction worked well with all three mineral acids, but the effect on ash content was not the same in the three cases. For sulfuric acid, the ash content did not vary significantly, whereas for nitric acid and hydrochloric acid, the ash content after extraction decreased from $13 \%$ to approximately $4 \%$ (Figure 1a). Analysis of the ash components showed that calcium and phosphorus are significantly reduced in the latter cases, whereas with sulfuric acid the calcium concentration was still similar to the initial one (Figure $1 \mathrm{~b}$ ). In view of the low solubility of calcium sulfate, this was a predictable observation: calcium phosphate in the hydrochar is replaced by calcium sulfate. The sulfate content is included in the "other" fraction in Figure 1b. From these results it was concluded that sulfuric acid was suitable for phosphorus extraction. However, with high calcium hydrochars, the ash content did not decrease when 


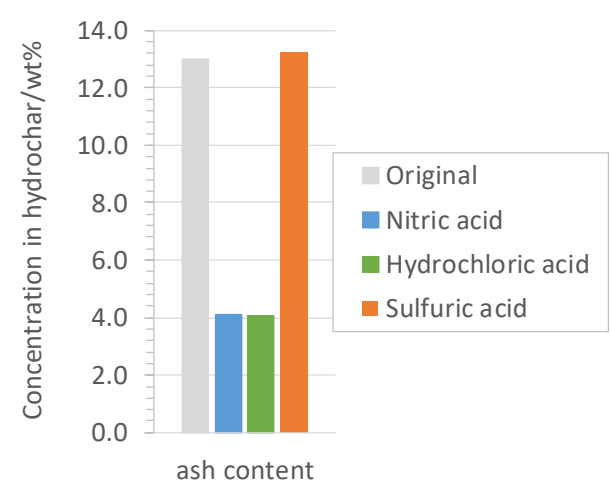
phosphate from hydrochar.

phosphorus was removed. If a lower ash content was desired, sulfuric acid was not a valuable choice and hydrochloric acid or nitric acid should be used.

When mineral acids were used for phosphorus extraction from sewage sludge ashes, sulfuric acid was the reagent of choice for economic reasons, although it increased the amounts of inorganic residues.(Ottosen et al., 2013) In contrast, in the present case the organic nature of the by-product was a game changer: sulfate deposits deteriorated the product properties.

When using nitric acid and hydrochloric acid ash contents were clearly reduced (Figure 1a), and in particular calcium and phosphorus concentration in the acids (Figure 1b). Therefore, it can be concluded that these two mineral acids were very efficient in dissolving of calcium

a)

244

245

246

247

248

249

250

251

252

253

254

255

256

257

258

Figure 1. Ash content (a) and concentration of different metal oxides (b) in hydrochar, in the original sample and after extractions with different mineral acids.

\section{Phosphorus extraction of different hydrochar samples}

Phosphorus extraction and ash reduction were successful with hydrochar from the OFMSW. With the aim to evaluate the scope of the process, it was applied to several hydrochar samples from the FP-7 NEWAPP project. In the latter, organic residual feedstocks were processed by HTC on industrial scale, namely sewage sludge, orange peel waste (OPW) and green and garden prunings.("Industrial Scale Hydrothermal Carbonization: new applications for wet biomass waste," 2016) The hydrochar samples had a different ash content, from high ash (27\% sewage sludge and $18 \%$ garden-pruning) to lower ash (OPW 7\%, Figure 2a). In addition, ash compositions were significantly different since hydrochar originating from sewage sludge contained the expected increased phosphorus content, while for the other two samples the concentration of this element was rather low (Figure $2 b$ ). 


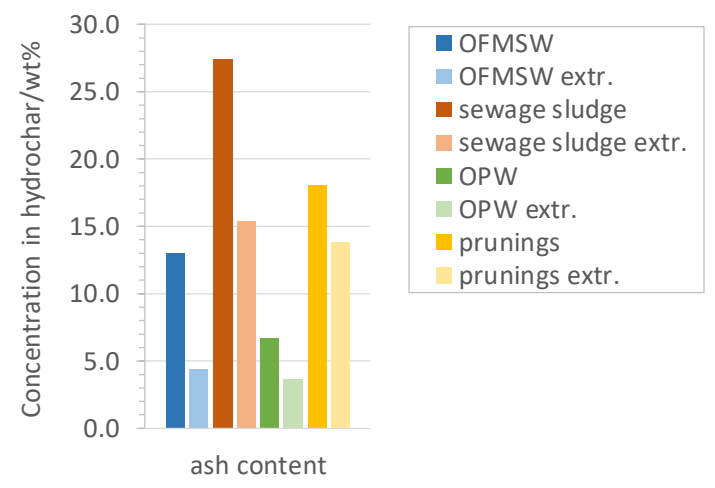

b)

\begin{tabular}{|c|c|c|c|}
\hline OFMSW & OFMSW extr. & sewage sludge & sewage sludge extr. \\
\hline OPW & OPW extr. & prunings & prunings extr. \\
\hline
\end{tabular}

Figure 2. Ash content (a) and concentration of different metal oxides (b) in hydrochar, measured for the original sample and after extractions with hydrochloric acid $\left(4 \%, 60^{\circ} \mathrm{C}, 4 \mathrm{~h}\right)$. Hydrochars were prepared from the organic fraction of municipal solid waste (OFMSW), sewage sludge, orange peel waste (OPW), and garden prunings.

The hydrochloric acid extraction process $\left(4 \%, 60^{\circ} \mathrm{C}, 4 \mathrm{~h}\right)$ was able to reduce the phosphorus content to almost zero in all cases (Figure $2 \mathrm{~b}$ ). When the phosphorus content was high (for example, in the sample obtained from sewage sludge), the ash content was also significantly reduced from $27 \%$ to $15 \%$. At low phosphorus content (OPW, garden prunings), the gain in ash reduction was rather low (Figure 2a). It was remarkable that calcium was almost completely removed in the sewage sludge-derived hydrochar (initially 7\%), as well as in the OFMSW derived hydrochar, but not in the garden-pruning derived one (originally $5 \%$ ). In the latter case, the calcium content was reduced by only half. Therefore, these data showed that calcium reduction was more efficient when phosphate was present at the same time. Therefore, it was concluded that the present extraction method generally worked well for the phosphorus extraction and was effective for reducing the ashes when both elements, calcium and phosphorus, were present in significant amounts. 
Performance of the extracted hydrochar as solid fuel

It has already been shown that phosphorus extraction can be carried out with the aim to achieve two goals simultaneously: the recovery of phosphorus and the ash reduction. The latter purpose is interesting when hydrochar is commercialized as solid fuel. Therefore, relevant properties of the material after extraction were analyzed and evaluated. Only samples produced with nitric acid and hydrochloric acid were considered since sulfuric acid was previously discarded for improving fuel quality.

The first and most important feature of a solid fuel is its energy content, quantified as higher heating value (HHV). Table 2 shows that the HHV for various hydrochar samples increased by up to ten percent through the extraction process. This was due to two different facts: First, the $\mathrm{HHV}$ calculated on dry and ash-free base was not significantly affected by the extraction process, and, secondly, the ash content decreased. Since the latter did not contribute to total HHV (on a dry basis), the intrinsic energy was less diluted in the solid when it was removed.

The removal of the ash also affects the mass yield, which was reduced (Table 2). This was the penalty for the higher energy concentration in the extracted hydrochar. Therefore, the energy concentration compensates the mass loss and the balance for the amount of energy involved in a given amount of material was the same before and after the extraction process.

For environmental purposes, chlorine and sulfur are worrying elements in fuels. For the present treatments, extraction with hydrochloric acid increased the chlorine content by more than a factor of two (from $0.085 \%$ to $0.261 \%$ ). This indicated that washing the hydrochar sample (approx. $4 \mathrm{~g}$ ) with $100 \mathrm{~mL}$ of water, after treatment with $15 \mathrm{~mL}$ of dilute acid was not sufficient. However, higher water consumption was discarded as this would further worsen the economic and environmental balance. Clearly, the better option was to change the extracting agent to nitric acid. In this case, the chlorine content was halved (from $0.085 \%$ to $0.043 \%$ ).

A positive effect was also detected for the sulfur content. The latter decreased for both cases, hydrochloric acid and nitric acid treatment, by 20 and $65 \%$, respectively. However, the initial value was relatively high at $0.494 \%$, which was reduced to $0.169 \%$. After treatment, hydrochar complied with the requirements of international standard ISO 17225-8: 2016.(International Organization for Standardization, n.d.) For the TA2 specification, the sulfur content must be less than $0.2 \%$. With respect to the chlorine content, both the original and the nitric acidtreated sample satisfied the requirement of $0.1 \%$ or less.

In summary, it can be stated that the phosphorus extraction with nitric acid improved the hydrochar characteristics as a solid fuel. Not only was the ash content reduced below $5 \%$, but also element concentrations critical for combustion such as chlorine and sulfur were reduced. By this, the requirements of ISO 17225-8 are fulfilled.

\section{Recovery of phosphorus as a solid}

In general, phosphorus precipitation is undergraduate chemistry and does not require much attention. In the present case, however, HTC process water was employed for the preparation of the extraction liquids. Since dissolved material can affect both the precipitation process and the solids properties, these issues were also studied in detail, and related information is included in the Electronic Supplementary Information (ESI).

X-ray powder diffraction (Figure S3) and FTIR spectroscopy (Figure S5) showed the formation of calcium hydrogen phosphate (brushite) by neutralization of the extraction liquid. From this solid, phosphorus is available to plants as it is dissolved by neutral water (Figure S8), while 
calcination (or combustion) converted it into less soluble species. In summary, the results confirmed that the OFMSW can provide a solid phosphorus fertilizer together with a high quality solid fuel.

Environmental performance - Impact scores for laboratory-scale phosphorus extraction The LCA was carried out considering twelve scenarios, starting from experimental conditions and real phosphorus content and adding potential optimization events to the study (for more details, see the Materials and Methods section).

Table 3 shows the environmental impact scores modelled for the baseline scenario (scenario 1 in Table 3; nitric acid) and two other scenarios with different acids (scenarios 2 and 3 in Table 3 ; hydrochloric acid and sulfuric acid) expressed in category-specific units. Overall, three major observations are seen. First, impact scores are positive in most impact categories, suggesting that the treatment of biowaste with phosphorus recovery through hydrothermal carbonization is expected to result in environmental burden. This environmental burden is mainly due to the need to produce relatively large amounts of acids and bases for $\mathrm{P}$ recovery. Secondly, negative impact scores are seen for three impact categories, namely particulate matter formation, acidification (in scenarios 2 and 3 ) and water resource depletion. This suggests that environmental benefits are expected for these impact categories when biowaste is treated hydrothermally with recovery of phosphorus. Our analysis shows that these benefits are mainly due to the avoidance of fossil coal heat generation when using hydrochar as a solid fuel (in terms of particulate matter and acidification impacts). Negative scores for water resource depletion, however, are due to the avoided use of water in the upstream processes for the production of base (potassium hydroxide as example of a base from the ecoinvent database). The third finding is that phosphorus extraction with $\mathrm{H}_{2} \mathrm{SO}_{4}$ is environmentally friendly in twelve out of 15 impact categories (excluding particulate matter, water resource depletion and, in some cases, acidification) compared to extraction with $\mathrm{HNO}_{3}$ or $\mathrm{HCl}$. This is due to lower amounts of sulfuric acid (on a mass basis) needed for extraction per treated waste unit. 


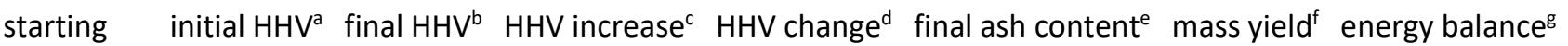

\begin{tabular}{|c|c|c|c|c|c|c|c|c|}
\hline entry & material & {$[\mathrm{MJ} / \mathrm{kg}]$} & {$[\mathrm{MJ} / \mathrm{kg}]$} & [\%DRY] & [\%DAF] & [\%] & [\%] & [\%] \\
\hline 1 & OFMSW & 27.9 & 30.6 & 9.6 & -0.3 & 34 & 86 & 94.2 \\
\hline 2 & OPW & 24.1 & 25.4 & 5.5 & 2.2 & 55 & 92 & 97.1 \\
\hline 3 & prunings & 20.4 & 22.3 & 9.5 & 4.2 & 77 & 90 & 98.6 \\
\hline
\end{tabular}

${ }^{\mathrm{a}} \mathrm{HHV}$ of hydrochar before extraction on dry base. ${ }^{\mathrm{b}} \mathrm{HHV}$ of hydrochar after extraction on dry base. ${ }^{\mathrm{c}}$ Change in $\mathrm{HHV}$ caused by the extraction procedure on dry base. ${ }^{d}$ Change in HHV caused by the extraction procedure on dry and ash-free (DAF) base. ${ }^{e}$ Final ash content compared to the initial one. ${ }^{f}$ Mass yield for hydrochar after the extraction procedure. ${ }^{g}$ Energy balance considering hydrochar as an energy carrier and comparing the final energy amount (mass x HHV) with the initial one (Formula: energy balance $=($ final HHV $x$ mass yield $) /$ initial $\mathrm{HHV})$. 


\begin{tabular}{|c|c|c|c|c|}
\hline \multirow[b]{2}{*}{ Impact category } & \multirow[b]{2}{*}{ Unit } & \multicolumn{3}{|c|}{ Impact score } \\
\hline & & $\mathrm{HNO}_{3}$ & $\mathrm{HCl}$ & $\mathrm{H}_{2} \mathrm{SO}_{4}$ \\
\hline Climate change (GWP) & kg CO2 eq & $5.19 \mathrm{E}-01$ & 2.91E-01 & $1.50 \mathrm{E}-01$ \\
\hline Ozone depletion & kg CFC-11 eq & $4.82 \mathrm{E}-08$ & $8.85 \mathrm{E}-08$ & $3.94 \mathrm{E}-08$ \\
\hline Human toxicity, cancer effects & CTUh & $1.88 \mathrm{E}-08$ & $2.44 \mathrm{E}-08$ & $1.61 \mathrm{E}-08$ \\
\hline Human toxicity, non-cancer effects & CTUh & 7.70E-08 & $1.30 \mathrm{E}-07$ & $6.68 \mathrm{E}-08$ \\
\hline Particulate matter & kg PM2.5 eq & $-9.03 E-05$ & $-1.45 \mathrm{E}-04$ & $-1.09 E-04$ \\
\hline Ionizing radiation $\mathrm{HH}$ & kBq U235 eq & $9.33 \mathrm{E}-02$ & $1.27 \mathrm{E}-01$ & 8.67E-02 \\
\hline Photochemical ozone formation & kg NMVOC eq & $1.70 \mathrm{E}-03$ & $1.35 \mathrm{E}-03$ & $1.09 \mathrm{E}-03$ \\
\hline Acidification & molc $\mathrm{H}+\mathrm{eq}$ & 8.00E-04 & $-6.49 \mathrm{E}-05$ & $-4.37 \mathrm{E}-04$ \\
\hline Terrestrial eutrophication & molc $\mathrm{Neq}$ & $6.97 \mathrm{E}-03$ & $2.08 \mathrm{E}-03$ & $1.14 \mathrm{E}-03$ \\
\hline Freshwater eutrophication & kg P eq & $8.56 \mathrm{E}-05$ & $1.50 \mathrm{E}-04$ & $5.88 \mathrm{E}-05$ \\
\hline Marine eutrophication & $\mathrm{kg} \mathrm{N} \mathrm{eq}$ & 7.61E-04 & $6.17 \mathrm{E}-04$ & $5.14 \mathrm{E}-04$ \\
\hline Freshwater ecotoxicity & CTUe & $4.41 \mathrm{E}+00$ & $5.48 \mathrm{E}+00$ & $3.92 E+00$ \\
\hline Land use & kg C deficit & $6.69 \mathrm{E}-01$ & $6.46 \mathrm{E}-01$ & $5.31 \mathrm{E}-01$ \\
\hline Water resource depletion & m3 water eq & $-7.1 \mathrm{E}-04$ & $-5.8 \mathrm{E}-04$ & $-7.0 \mathrm{E}-04$ \\
\hline Mineral, fossil and renewable resource depletion & kg Sb eq & 3.01E-05 & 4.17E-05 & 4.47E-05 \\
\hline
\end{tabular}

365

366

367

Table 3. Impact scores in category-specific units for acid-based P extraction using $\mathrm{HNO}_{3}, \mathrm{HCl}$ or $\mathrm{H}_{2} \mathrm{SO}_{4}$ (scenarios 1,2 and 3 in Table 1, respectively).

368

369 Can phosphorus extraction bring environmental benefits?

370 Using the experimental conditions from the laboratory scale extractions, only limited

371 environmental benefits were noted. It should be further examined if benefits were reinforced

372 in optimized extraction conditions (lower acid level) or for more appropriate cases (higher

373 phosphorus content in hydrochar).

374 A relatively large contribution of acid and base used for extraction for all impact scores

375 indicates that there is significant potential for environmental optimization (eco-design):

376 reduction of acid and base levels during upscaling. In fact, the results presented in Figure 3 
show that if the amounts of acids and bases are reduced by a factor of 10 , which is not unrealistic when scaling from the bench to the pilot scale, the impact scores are reduced. The largest decrease was observed for the impact category freshwater ecotoxicity (where impact scores decrease by a factor of 100). For other impact categories, a reduction by a factor of up to 10 applies. In some cases impact scores become negative when amount of acid and base is reduced. This suggests that the environmental benefits of avoiding the burning of fossil coal in combination with the environmental benefits of avoiding the compositing of biowaste outweigh the burden of hydrothermal treatment and phosphorus recovery. This is the case for a total of 9 out of 15 impact categories, including climate change. In 11 out of 15 impact categories, impact scores are comparable to the system without phosphorus extraction. They are higher for two impact categories (ionizing radiation and freshwater ecotoxicity) and lower for two impact categories (freshwater eutrophication and water resource depletion) than for systems without phosphorus extraction.

A comparison with systems in which hydrochar contained larger amounts of phosphorus (scenarios 7-9 in Table 3) showed that impact scores were comparable to scenarios 1-3, suggesting that the benefits of obtaining relatively large quantities of phosphorus were not sufficient to outweigh the environmental burden (Figure S9 and Figure S10). Even if the amounts of acids and bases were optimized, the environmental benefits of $P$ extraction were relatively low compared to the system without phosphorus extraction.

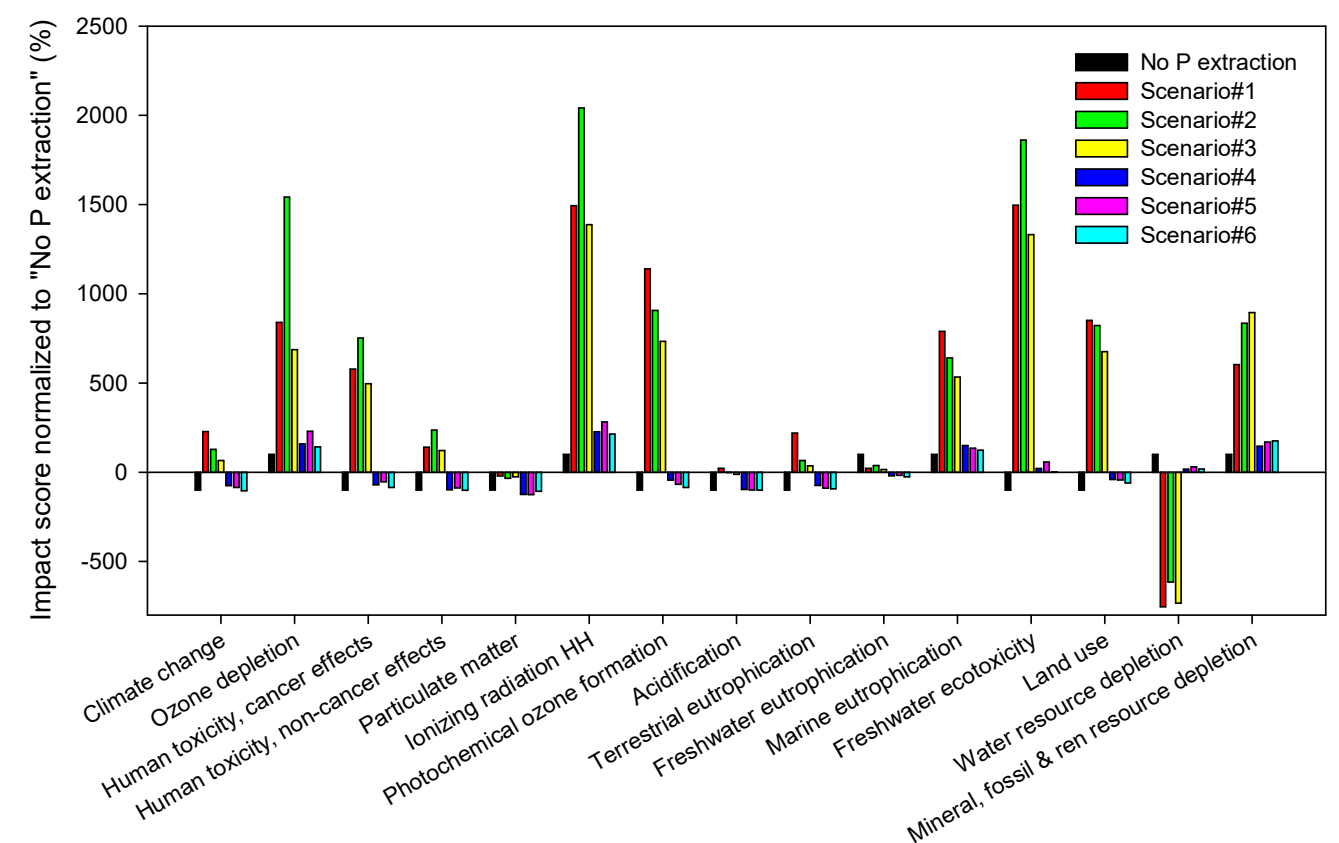

397

Figure 3. Impact scores for scenarios 1-6 in Table 3; expressed in \% and normalized internally to the "No phosphorus extraction" scenario, for which impacts are equal either 100\% (for positive impact scores) or -100\% (for negative impact scores).

401 
403 The OFMSW has been proposed as an alternative phosphorus reservoir for phosphorus recovery and solid fuel production. It has been shown that phosphorus can be extracted from

hydrochar with mineral acid with high efficiency. At high phosphorus content, the ash content decreased accordingly when nitric acid or hydrochloric acid was used for the extraction. In terms of fuel properties, nitric acid was the preferred mineral acid for extraction as the chlorine and sulfur content of the hydrochar decreased. This further improved the fuel properties of hydrochar and the latter even met the standard requirements for good quality solid fuels.

When phosphate was precipitated from the extraction solution, a solid phosphor material was obtained. The latter released phosphorus again in neutral water, so it was predicted that it was readily available to the plants and the solid is suitable as a phosphorus fertilizer. It was concluded that it was technically feasible to produce a solid fuel and a phosphorus fertilizer from phosphorus-rich OFMSW. However, the environmental benefits were limited, as the LCA of this concept showed. Phosphorus extraction was a burden in almost all fifteen-impact categories, including climate change and resource depletion. It is therefore recommended to study the application of phosphorus-containing advanced hydrochar in agriculture and horticulture, without intermediate concentration by extraction. It is predicted that carbon storage benefits are combined with fertilizing effects.(Hitzl et al., 2018; Owsianiak et al., 2018)

\section{Acknowledgement}

The authors are grateful for the financial support received from the Spanish Ministry of Economy and Competiveness under the RTC-2015-4017-3 of the state programme "Research, Development and Innovation Oriented to the Challenges of Society"

\section{References}

Boudia, S., Zuddas, P., Fernane, F., Fiallo, M., Sharrock, P., 2018. Mineralogical transformation during hydroxyapatite dissolution in simple aqueous solutions. Chem. Geol. 477, 85-91. https://doi.org/https://doi.org/10.1016/j.chemgeo.2017.12.007

Burguete, P., Corma, A., Hitzl, M., Modrego, R., Ponce, E., Renz, M., 2016. Fuel and chemicals from wet lignocellulosic biomass waste streams by hydrothermal carbonization. Green Chem. 18, 1051-1060. https://doi.org/10.1039/c5gc02296g

Busch, D., Kammann, C., Grünhage, L., Müller, C., 2012. Simple biotoxicity tests for evaluation of carbonaceous soil additives: Establishment and reproducibility of four test procedures. J. Environ. Qual. 41, 1023-1032. https://doi.org/10.2134/jeq2011.0122

Busch, D., Stark, A., Kammann, C.I., Glaser, B., 2013. Genotoxic and phytotoxic risk assessment of fresh and treated hydrochar from hydrothermal carbonization compared to biochar from pyrolysis. Ecotoxicol. Environ. Saf. 97, 59-66. https://doi.org/10.1016/j.ecoenv.2013.07.003

Cha, J.S., Park, S.H., Jung, S.-C., Ryu, C., Jeon, J.-K., Shin, M.-C., Park, Y.-K., 2016. Production and utilization of biochar: A review. J. Ind. Eng. Chem. 40, 1-15. https://doi.org/10.1016/j.jiec.2016.06.002

Cieślik, B., Konieczka, P., 2017. A review of phosphorus recovery methods at various steps of wastewater treatment and sewage sludge management. The concept of "no solid waste generation" and analytical methods. J. Clean. Prod. 142, 1728-1740. https://doi.org/10.1016/j.jclepro.2016.11.116 
Dalias, P., Prasad, M., Mumme, J., Kern, J., Stylianou, M., Christou, A., 2018. Low-cost posttreatments improve the efficacy of hydrochar as peat replacement in growing media. J. Environ. Chem. Eng. 6, 6647-6652. https://doi.org/10.1016/j.jece.2018.10.042

Desmidt, E., Ghyselbrecht, K., Zhang, Y., Pinoy, L., Van der Bruggen, B., Verstraete, W., Rabaey, K., Meesschaert, B., 2015. Global Phosphorus Scarcity and Full-Scale P-Recovery Techniques: A Review. Crit. Rev. Environ. Sci. Technol. 45, 336-384. https://doi.org/10.1080/10643389.2013.866531

Ettarh, C., Galwey, A.K., 1996. A kinetic and mechanistic study of the thermal decomposition of calcium nitrate. Thermochim. Acta 288, 203-219. https://doi.org/https://doi.org/10.1016/S0040-6031(96)03052-3

European Commission, 2017. Communication from the Commission to the European Parliament, the Council, the European Economic and Social Committee and the Committee of the Regions on the 2017 list of Critical Raw Materials for the EU [WWW Document]. URL http://eur-lex.europa.eu/legalcontent/EN/ALL/?uri=COM:2017:0490:FIN

Fornes, F., Belda, R.M., 2017. Acidification with nitric acid improves chemical characteristics and reduces phytotoxicity of alkaline chars. J. Environ. Manage. 191, 237-243. https://doi.org/http://dx.doi.org/10.1016/j.jenvman.2017.01.026

Funke, A., Ziegler, F., 2010. Hydrothermal carbonization of biomass: A summary and discussion of chemical mechanisms for process engineering. Biofuels, Bioprod. Biorefining 4, 160177. https://doi.org/10.1002/bbb.198

Hauschild, M.Z., Goedkoop, M., Guinée, J., Heijungs, R., Huijbregts, M., Jolliet, O., Margni, M., De Schryver, A., Humbert, S., Laurent, A., Sala, S., Pant, R., 2013. Identifying best existing practice for characterization modeling in life cycle impact assessment. Int. J. Life Cycle Assess. 18, 683-697. https://doi.org/10.1007/s11367-012-0489-5

Hitzl, M., Corma, A., Pomares, F., Renz, M., 2015. The hydrothermal carbonization (HTC) plant as a decentral biorefinery for wet biomass. Catal. Today 257, 154-159. https://doi.org/10.1016/j.cattod.2014.09.024

Hitzl, M., Mendez, A., Owsianiak, M., Renz, M., 2018. Making hydrochar suitable for agricultural soil: A thermal treatment to remove organic phytotoxic compounds. J. Environ. Chem. Eng. 6, 7029-7034. https://doi.org/https://doi.org/10.1016/j.jece.2018.10.064

Hu, B., Wang, K., Wu, L., Yu, S.H., Antonietti, M., Titirici, M.M., 2010. Engineering carbon materials from the hydrothermal carbonization process of biomass. Adv. Mater. 22, 813828. https://doi.org/10.1002/adma.200902812

Idowu, I., Li, L., Flora, J.R. V, Pellechia, P.J., Darko, S.A., Ro, K.S., Berge, N.D., 2017. Hydrothermal carbonization of food waste for nutrient recovery and reuse. Waste Manag. 69, 480-491. https://doi.org/10.1016/j.wasman.2017.08.051

ILCD Handbook: General guide for Life Cycle Assessment - Detailed guidance, 2010. . European Commission.

Industrial Scale Hydrothermal Carbonization: new applications for wet biomass waste [WWW Document], 2016. URL http://www.newapp-project.eu/en/public-library/send/2-publiclibrary/3-industrial-scale-hydrothermal-carbonization-new-applications-for-wet-biomasswaste.html (accessed 4.26.18). 
International Organization for Standardization, n.d. Solid biofuels - Fuel specifications and classes - Part 8: Graded thermally treated and densified biomass fuels (ISO/TS 172258:2016) [WWW Document]. 2016. URL https://www.iso.org/standard/71915.html (accessed 4.27.18).

ISO 14044:2006 Environmental management -- Life cycle assessment -- Requirements and guidelines, 2006. . International Standards Organization.

Kambo, H.S., Dutta, A., 2015. A comparative review of biochar and hydrochar in terms of production, physico-chemical properties and applications. Renew. Sustain. Energy Rev. 45, 359-378. https://doi.org/10.1016/j.rser.2015.01.050

Kempegowda, R.S., Tran, K.-Q., Skreiberg, Ø., 2017. Techno-economic assessment of integrated hydrochar and high-grade activated carbon production for electricity generation and storage, in: N., F., A., R., V., S. (Eds.), . Elsevier Ltd, SINTEF Energy Research, P.O. Box 4761 Sluppen, Trondheim, Norway, pp. 341-348. https://doi.org/10.1016/j.egypro.2017.07.223

Lafon, J.P., Champion, E., Bernache-Assollant, D., 2008. Processing of AB-type carbonated hydroxyapatite $\mathrm{Ca}_{10}-\mathrm{x}\left(\mathrm{PO}_{4}\right)_{6}-\mathrm{x}\left(\mathrm{CO}_{3}\right) \mathrm{x}(\mathrm{OH})_{2}-\mathrm{x}-2 \mathrm{y}\left(\mathrm{CO}_{3}\right) \mathrm{y}$ ceramics with controlled composition. J. Eur. Ceram. Soc. 28, 139-147. https://doi.org/10.1016/j.jeurceramsoc.2007.06.009

Landi, E., Celotti, G., Logroscino, G., Tampieri, A., 2003. Carbonated hydroxyapatite as bone substitute. J. Eur. Ceram. Soc. 23, 2931-2937. https://doi.org/https://doi.org/10.1016/S0955-2219(03)00304-2

Lang, Q., Zhang, B., Liu, Z., Jiao, W., Xia, Y., Chen, Z., Li, D., Ma, J., Gai, C., 2019. Properties of hydrochars derived from swine manure by $\mathrm{CaO}$ assisted hydrothermal carbonization. J. Environ. Manage. 233, 440-446. https://doi.org/10.1016/j.jenvman.2018.12.072

Lu, H., Reddy, E.P., Smirniotis, P.G., 2006. Calcium Oxide Based Sorbents for Capture of Carbon Dioxide at High Temperatures. Ind. Eng. Chem. Res. 45, 3944-3949. https://doi.org/10.1021/ie051325x

Lysikov, A.I., Salanov, A.N., Okunev, A.G., 2007. Change of $\mathrm{CO}_{2}$ Carrying Capacity of $\mathrm{CaO}$ in Isothermal Recarbonation-Decomposition Cycles. Ind. Eng. Chem. Res. 46, 4633-4638. https://doi.org/10.1021/ie0702328

Melia, P.M., Cundy, A.B., Sohi, S.P., Hooda, P.S., Busquets, R., 2017. Trends in the recovery of phosphorus in bioavailable forms from wastewater. Chemosphere 186, 381-395. https://doi.org/10.1016/j.chemosphere.2017.07.089

New technological applications for wet biomass waste stream products [WWW Document], n.d. URL https://cordis.europa.eu/project/rcn/110741/factsheet/en

Ottosen, L.M., Kirkelund, G.M., Jensen, P.E., 2013. Extracting phosphorous from incinerated sewage sludge ash rich in iron or aluminum. Chemosphere 91, 963-969. https://doi.org/https://doi.org/10.1016/j.chemosphere.2013.01.101

Owsianiak, M., Brooks, J., Renz, M., Laurent, A., 2018. Evaluating climate change mitigation potential of hydrochars: compounding insights from three different indicators. GCB Bioenergy 10, 230-245. https://doi.org/10.1111/gcbb.12484

Owsianiak, M., Ryberg, M.W., Renz, M., Hitzl, M., Hauschild, M.Z., 2016. Environmental Performance of Hydrothermal Carbonization of Four Wet Biomass Waste Streams at Industry-Relevant Scales. ACS Sustain. Chem. Eng. 4, 6783-6791. 
https://doi.org/10.1021/acssuschemeng.6b01732

Poinern, G.J.E., Brundavanam, R., Le, X.T., Djordjevic, S., Prokic, M., Fawcett, D., 2011. Thermal and ultrasonic influence in the formation of nanometer scale hydroxyapatite bio-ceramic. Int. J. Nanomedicine 6, 2083-2095. https://doi.org/10.2147/IJN.S24790

Singh, A., Purohit, K.M., 2011. Chemical Synthesis, Characterization and Bioactivity Evaluation of Hydroxyapatite Prepared from Garden snail (Helix aspersa). J. Bioprocess. Biotech. https://doi.org/10.4172/2155-9821.1000104

Smith, A.M., Whittaker, C., Shield, I., Ross, A.B., 2018. The potential for production of high quality bio-coal from early harvested Miscanthus by hydrothermal carbonisation. Fuel 220, 546-557. https://doi.org/10.1016/j.fuel.2018.01.143

Straub, D.A., 2007. Calcium Supplementation in Clinical Practice: A Review of Forms, Doses, and Indications. Nutr. Clin. Pract. 22, 286-296. https://doi.org/10.1177/0115426507022003286

Tamaki, M., Kannan, S., Jaidev, T., Raj, S., 2009. Physical characterization of dibasic calcium phosphate dihydrate and anhydrate. J. Pharm. Sci. 98, 905-916. https://doi.org/10.1002/jps.21443

Tamimi, F., Sheikh, Z., Barralet, J., 2012. Dicalcium phosphate cements: Brushite and monetite. Acta Biomater. 8, 474-487. https://doi.org/https://doi.org/10.1016/j.actbio.2011.08.005

Titirici, M.-M., White, R.J., Falco, C., Sevilla, M., 2012. Black perspectives for a green future: Hydrothermal carbons for environment protection and energy storage. Energy Environ. Sci. 5, 6796-6822. https://doi.org/10.1039/c2ee21166a

Titirici, M.M., Thomas, A., Yu, S.-H., Mueller, J.-O., Antonietti, M., 2007. A Direct Synthesis of Mesoporous Carbons with Bicontinuous Pore Morphology from Crude Plant Material by Hydrothermal Carbonization. Chem. Mater. 19, 4205-4212. https://doi.org/10.1021/cm0707408

Titirici, M.M., Thomas, A., Yu, S.H., Müller, J.O., Antonietti, M., 2007. A direct synthesis of mesoporous carbons with bicontinuous pore morphology from crude plant material by hydrothermal carbonization. Chem. Mater. 19, 4205-4212. https://doi.org/10.1021/cm0707408

Ucar, S., Bjørnøy, S.H., Bassett, D.C., Strand, B.L., Sikorski, P., Andreassen, J.-P., 2017. Transformation of brushite to hydroxyapatite and effects of alginate additives. J. Cryst. Growth 468, 774-780. https://doi.org/https://doi.org/10.1016/j.jcrysgro.2016.11.019

Wang, T., Zhai, Y., Zhu, Y., Gan, X., Zheng, L., Peng, C., Wang, B., Li, C., Zeng, G., 2018. Evaluation of the clean characteristics and combustion behavior of hydrochar derived from food waste towards solid biofuel production. Bioresour. Technol. 266, 275-283. https://doi.org/10.1016/j.biortech.2018.06.093

Weidema, B.P., Bauer, C., Hischier, R., Mutel, C., Nemecek, T., Reinhard, J., Vadenbo, C.O., Wernet, G., 2013. Overview and methdology - Data quality guideline for the ecoinvent database version 3 .

Yadav, R.S., Meena, S.C., Patel, S.I., Patel, K.I., Akhtar, M.S., Yadav, B.K., Panwar, J., 2012. Bioavailability of Soil P for Plant Nutrition BT - Farming for Food and Water Security, in: Lichtfouse, E. (Ed.), . Springer Netherlands, Dordrecht, pp. 177-200. https://doi.org/10.1007/978-94-007-4500-1_8 
Zhang, L., Zeng, G., Dong, H., Chen, Y., Zhang, J., Yan, M., Zhu, Y., Yuan, Y., Xie, Y., Huang, Z., 2017. The impact of silver nanoparticles on the co-composting of sewage sludge and agricultural waste: Evolutions of organic matter and nitrogen. Bioresour. Technol. 230, 132-139. https://doi.org/https://doi.org/10.1016/j.biortech.2017.01.032

Zhang, L., Zhang, J., Zeng, G., Dong, H., Chen, Y., Huang, C., Zhu, Y., Xu, R., Cheng, Y., Hou, K., Cao, W., Fang, W., 2018. Multivariate relationships between microbial communities and environmental variables during co-composting of sewage sludge and agricultural waste in the presence of PVP-AgNPs. Bioresour. Technol. 261, 10-18.

https://doi.org/https://doi.org/10.1016/j.biortech.2018.03.089 
Borja Oliver-Tomas, ${ }^{\mathrm{a}, \mathrm{c}}$ Martin Hitzl, ${ }^{\mathrm{a}}$ Mikołaj Owsianiak, ${ }^{\mathrm{b}}$ Michael Renz*c

595

596

597

598

599

600

601

602

603

604

605

606

607

a Ingelia, S.L., Spain

${ }^{\mathrm{b}}$ Technical University of Denmark, Denmark

c Instituto de Tecnología Química (UPV-CSIC), Spain; E-mail: mrenz@itq.upv.es

\section{Content}

Experimental details on the recovery of phosphorus as a solid

Figure S1. Ash composition of hydrochar obtained from ICP-OES analysis. Amounts are expressed as weight\% of the oxides of the elements. Initial ash content was $13 \mathrm{wt} \%$ on dry base.

Figure S2.Phosphorus extraction efficiency with different mineral acids at different temperatures.

Figure S3. XRD pattern of the precipitate (a) and of the precipitate after calcination (b).

Figure S4. XRD pattern of the hydrochar before extraction.

Figure S5. FTIR spectra a) of the precipitate and the precipitate after calcination and b) of the precipitate in comparison with brushite.

Figure S6. Thermogravimetric (TG) analysis of the precipitate under nitrogen atmosphere.

Figure S7. Composition of a) precipitate and b) precipitate after calcination, measured by ICPOES.

Figure S8. Solubility of the two main components of the precipitate.

Figure 59. Impact scores for scenarios 1-3 and 7-9 in Table 3, expressed in \%, normalized internally to "No phosphorus extraction" scenario, for which impacts are equal either $100 \%$ (for positive impact scores) or $-100 \%$ (for negative impact scores).

Figure S10. Impact scores for scenarios 1-3 and 10-12 in Table 3, expressed in \%, normalized internally to "No phosphorus extraction" scenario, for which impacts are equal either $100 \%$ (for positive impact scores) or $-100 \%$ (for negative impact scores). 


\section{Recovery of phosphorus as a solid}

For transportation means, solid phosphorus is preferred over dissolved and diluted phosphorus. Therefore, the precipitation of the phosphorus from the extraction solution was studied. By addition of lime $\left(\mathrm{Ca}(\mathrm{OH})_{2}\right) \mathrm{pH}$ was shifted to slightly alkaline (8-9.5) and up to quantitative precipitation (99\%) was achieved and the phosphor precipitate deeply analyzed. Precipitation process and solid product characteristics might be influenced by components of the HTC process water that was employed for the extraction (after adding concentrated mineral acid) with the aim to simulate real world conditions.

By X-ray powder diffraction (XRD) calcium hydrogen phosphate (brushite) was identified in the solid, contaminated by calcium carbonate (Figure S3a). As it was confirmed that calcium carbonate was not present in the starting material, i.e. the hydrochar employed in the extractions (Figure S4; at least not in crystalline form), it had to be concluded that the carbonate was formed by incorporation of ambient carbon dioxide, probably during the filtration processes in the laboratory. Hence, this might be avoided by changing the experimental setup. The XRD pattern of the hydrochar indicated the presence of sand and hydroxyapatite (Figure S4). The latter also reveals a potential origin of the phosphorus: up to $70 \%$ by weight of (human) bone is a modified form of hydroxyapatite, known as bone mineral.(Straub, 2007)

The presence of both components in the precipitate, calcium hydrogen phosphate and carbonate, was confirmed by IR spectroscopy (Figure S5). Calcium carbonate is evidenced by bands at wavenumbers of $1430 \mathrm{~cm}^{-1}, 890 \mathrm{~cm}^{-1}$ and $710 \mathrm{~cm}^{-1}$ (green dashed lines), being the first one the strongest and the most characteristic one.(Landi et al., 2003) Comparison of the spectrum with the one of brushite (Figure S5b; blue dashed lines) permits to detect characteristic bands such as $1645 \mathrm{~cm}^{-1}$ associated with water molecules in the lattice (Ucar et al., 2017) and associated with the presence of the $\mathrm{HPO}_{4}{ }^{2-}$ ion at $1135,1060,985,575$ and 525 $\mathrm{cm}^{-1}$.(Ucar et al., 2017) The band observed at $1385 \mathrm{~cm}^{-1}$ (red dashed line) indicated contamination with a small amount of nitrate from the extraction solution.(Lafon et al., 2008)

The presence of carbonate and nitrate species was further corroborated by their decomposition by calcination at $815^{\circ} \mathrm{C}$. Hence, after calcination, the XRD pattern indicated the presence of calcium hydroxyapatite and calcium phosphate (Figure S3b). In the FTIR spectrum, the characteristic bands for carbonate and nitrate at 1430 and $1385 \mathrm{~cm}^{-1}$ were clearly diminished (Figure S5a) whereas the characteristic phosphate band at $1030 \mathrm{~cm}^{-1}$ was clearly evidenced.(Poinern et al., 2011; Singh and Purohit, 2011) Therefore, it can be stated that both techniques confirmed a transformation of brushite and calcite during calcination.

When the decomposition process was elucidated in detail by thermogravimetric (TG) analysis, it was seen that two major weight losses occurred, namely up to $200^{\circ} \mathrm{C}$ and between 600 and $900{ }^{\circ} \mathrm{C}$ (Figure S6). Both losses were in accordance with literature reports for the involved materials. Differential scanning calorimetry has determined 190 to $200^{\circ} \mathrm{C}$ as desorption temperature of the crystal water molecules of dibasic calcium phosphate dihydrate.(Tamaki et al., 2009) In addition, calcium carbonate is transformed into calcium oxide at temperatures of $700{ }^{\circ} \mathrm{C}$ to $850^{\circ} \mathrm{C}$ (Lu et al., 2006; Lysikov et al., 2007) and nitrate breakdown occurred almost in the same interval $\left(680^{\circ} \mathrm{C}\right)$ under dynamic rising temperature conditions. (Ettarh and Galwey, 1996) The second weight loss was also in accordance with the behavior of mixed materials. Hence, thermal decomposition of carbonated apatite started at temperatures higher than 600 ${ }^{\circ} \mathrm{C}$ in inert atmosphere:(Lafon et al., 2008) by IR measurements it has been confirmed that 
667 after calcination in air at $600{ }^{\circ} \mathrm{C}$ decarbonatation had not occurred, whereas after the same 668 procedure at $800^{\circ} \mathrm{C}$ only one third of the initial amount remained.

669 Chemical composition of the precipitate was further analyzed and quantified, namely

670 phosphorus by inductively coupled plasma - optical emission spectroscopy (ICP-OES) and

671 calcium by $X$ ray fluorescence (XRF) spectroscopy. The combined results indicated a $41 \mathrm{wt} \%$

672 content of $\mathrm{CaHPO}_{4} \cdot 2 \mathrm{H}_{2} \mathrm{O}$ and a $47 \%$ content of $\mathrm{CaCO}_{3}$ in the precipitate (Figure S7a). After

673 calcination, $64 \mathrm{wt} \%$ of the obtained solid consisted of $\mathrm{Ca}_{3}\left(\mathrm{PO}_{4}\right)_{2}$ and $30 \mathrm{wt} \%$ of $\mathrm{CaO}$. There is a

674 small incoherency with the DRX pattern as $\mathrm{CaO}$ was not detected. However, this might be due

675 to an amorphous or nanocrystalline nature of the material.

676 For the suitability of a phosphorus-containing material as solid fertilizer, water solubility is

677 crucial. Plants absorb the inorganic phosphate either in the form of $\mathrm{HPO}_{4}{ }^{2-}$ or of $\mathrm{H}_{2} \mathrm{PO}_{4}{ }^{-}$from

678 the soil solution.(Yadav et al., 2012) However, brushite has been employed as a dicalcium

679 phosphate cement, suitable for bioceramics.(Tamimi et al., 2012) Therefore, it can be expected

680 that it possessed a low water solubility. In addition, hydroxyapatite is treated as a stable

681 mineral under surface Earth conditions and adopted as a proxy for paleo-environmental

682 reconstructions and in choice of remediation strategies.(Boudia et al., 2018) As a consequence,

683 it was mandatory to evaluate the solubility of the precipitate, so that it could be demonstrated

684 that the extracted and precipitated phosphorus fulfilled the minimum criteria as fertilizer.

685 From Figure S8 it can be seen that the phosphorus component dissolved well in neutral water, 686 whereas the calcite was only sparely soluble. For the calcined precipitate solubility was the 687 contrary (not shown): calcium oxide dissolved readily whereas the phosphorus did not dissolve 688 at all. From this is can be concluded that calcination of the precipitate, or combustion of 689 hydrochar, is detrimental for phosphorus availability for plant growth. However, phosphorus 690 as precipitate should be readily available for the plants. 


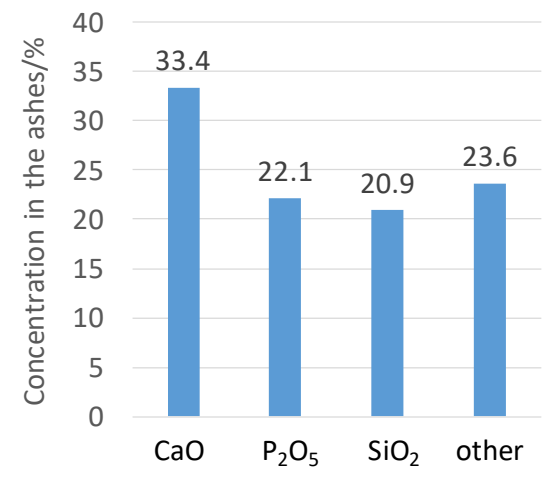

Figure S2.Phosphorus extraction efficiency with different mineral acids at different temperatures.

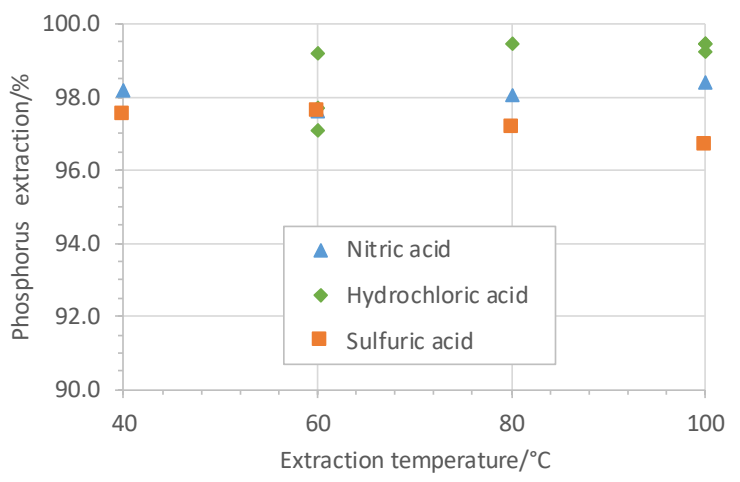

698

699

700 
Figure S3. XRD pattern of the precipitate (a) and of the precipitate after calcination (b).

a)

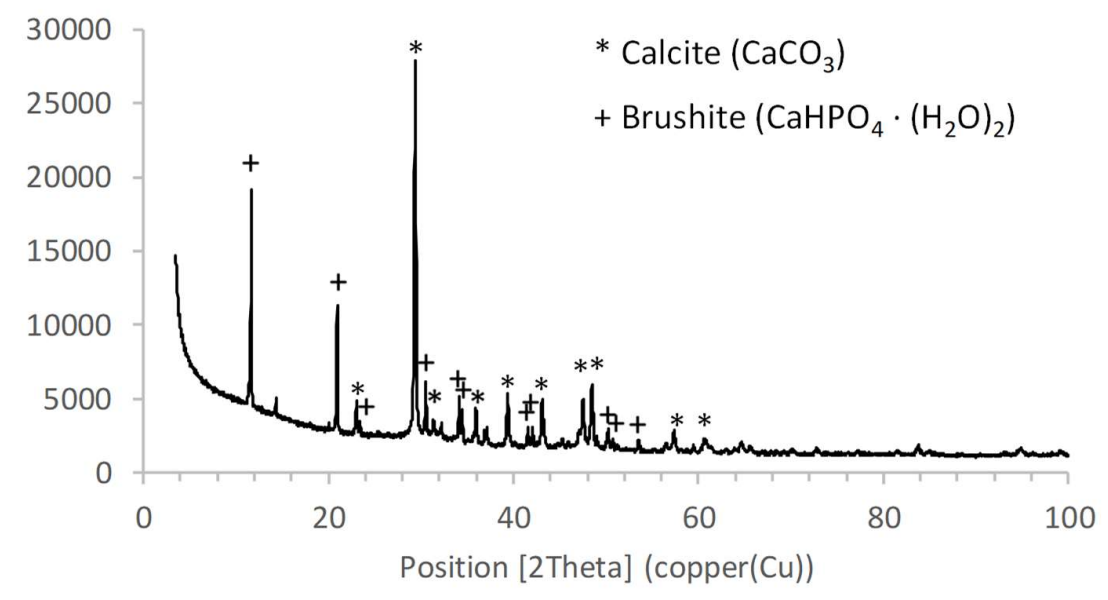

703

b) $\quad 10000$

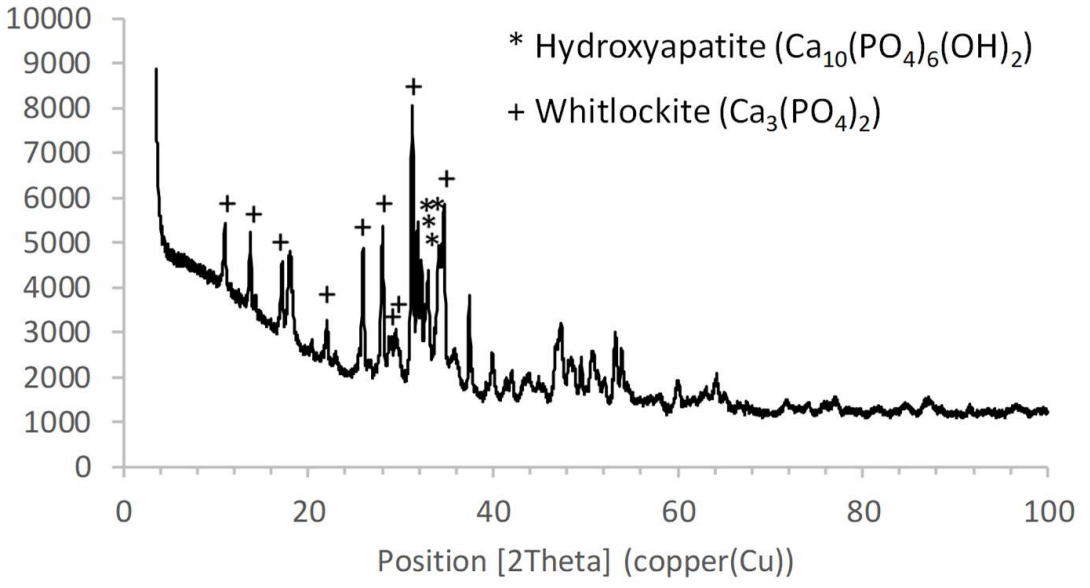

704

705

706

Figure S4. XRD pattern of the hydrochar before extraction.

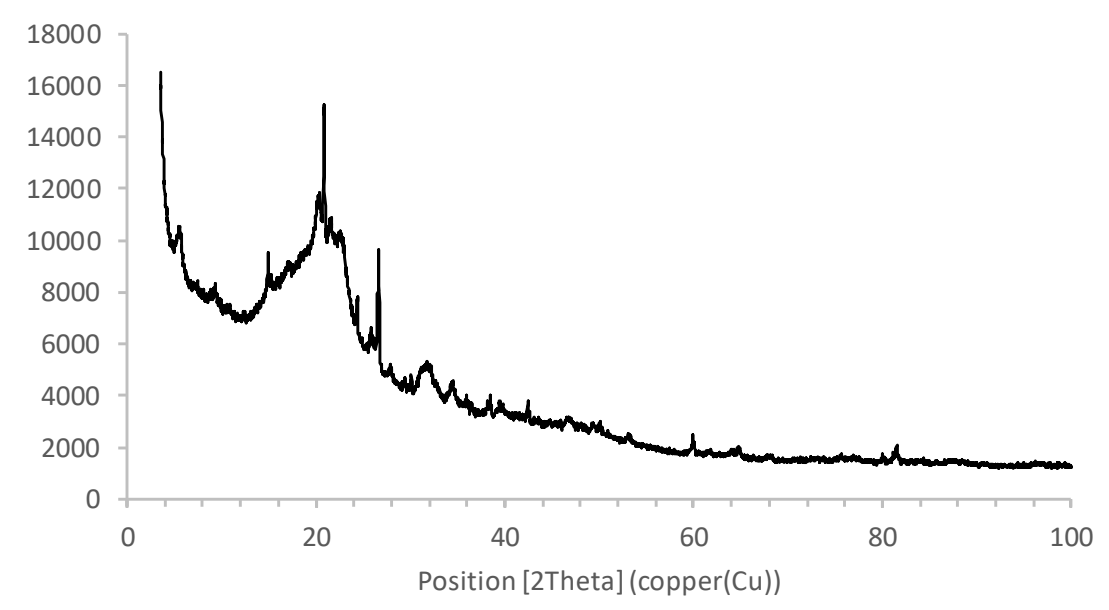


Figure S5. FTIR spectra a) of the precipitate and the precipitate after calcination and b) of the precipitate in

a)

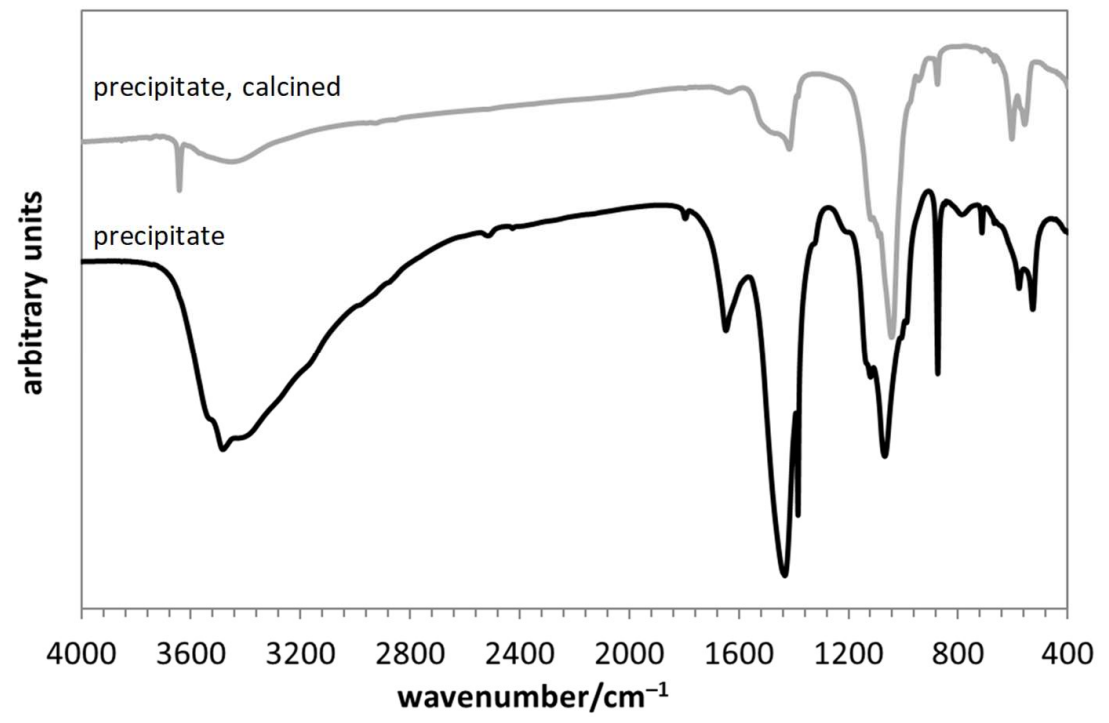

713 wavenumber $/ \mathrm{cm}^{-1}$

714

715

b

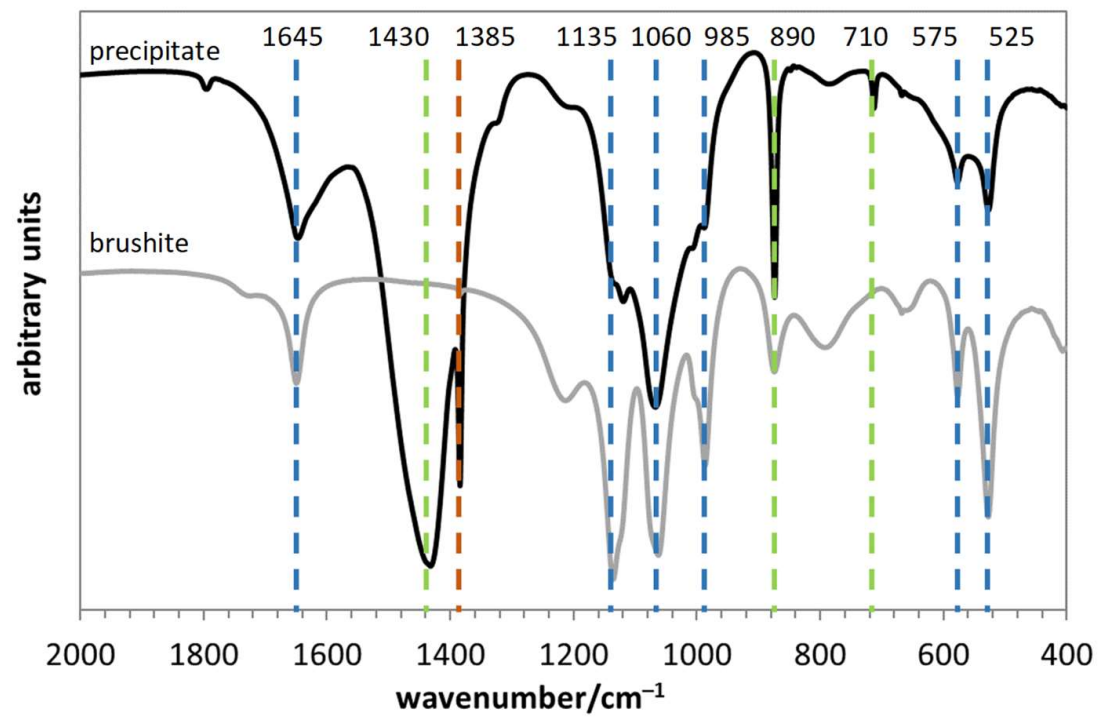

717 
721 Figure S6. Thermogravimetric (TG) analysis of the precipitate under nitrogen atmosphere.

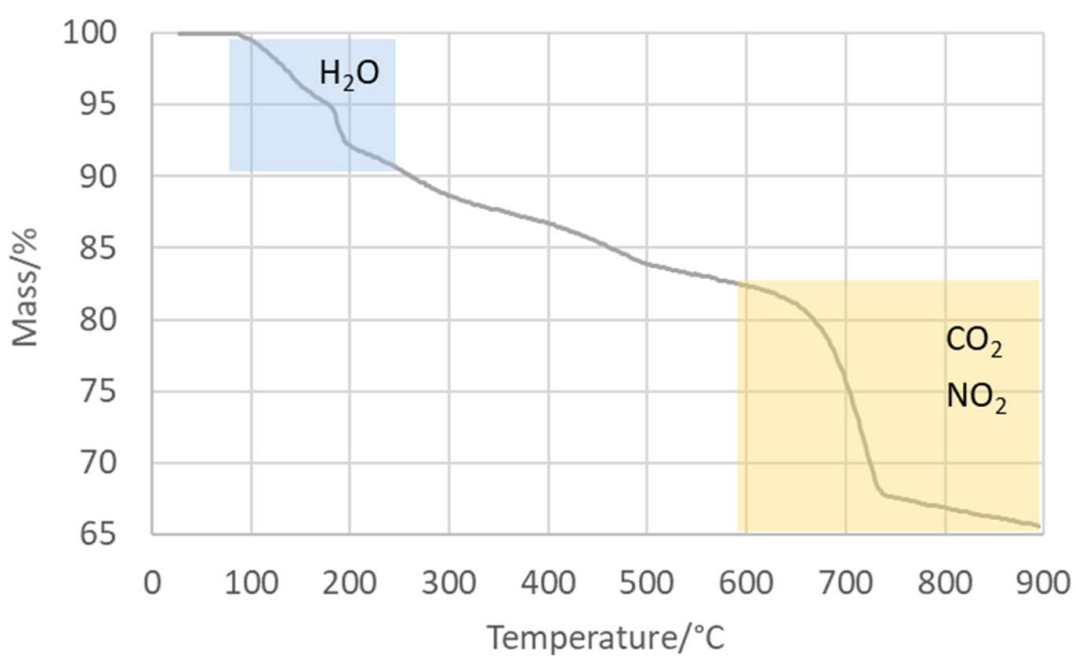

722

723

724

Figure S7. Composition of a) precipitate and b) precipitate after calcination, measured by ICP-OES.

a)

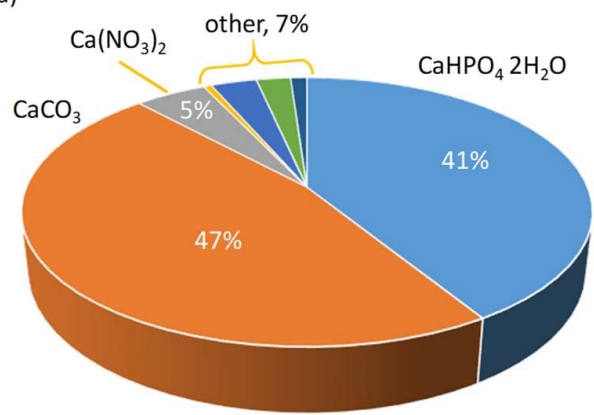

b)

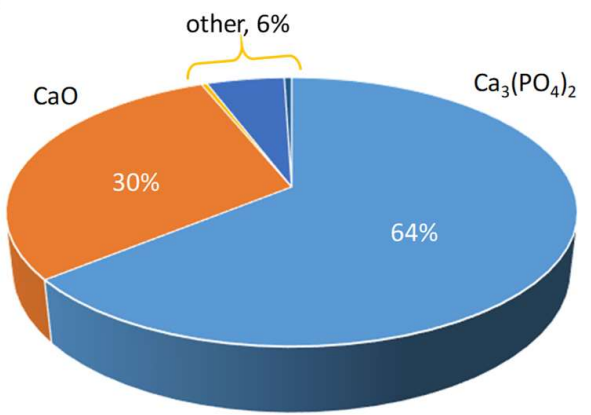

725

726

727

Figure S8. Solubility of the two main components of the precipitate.

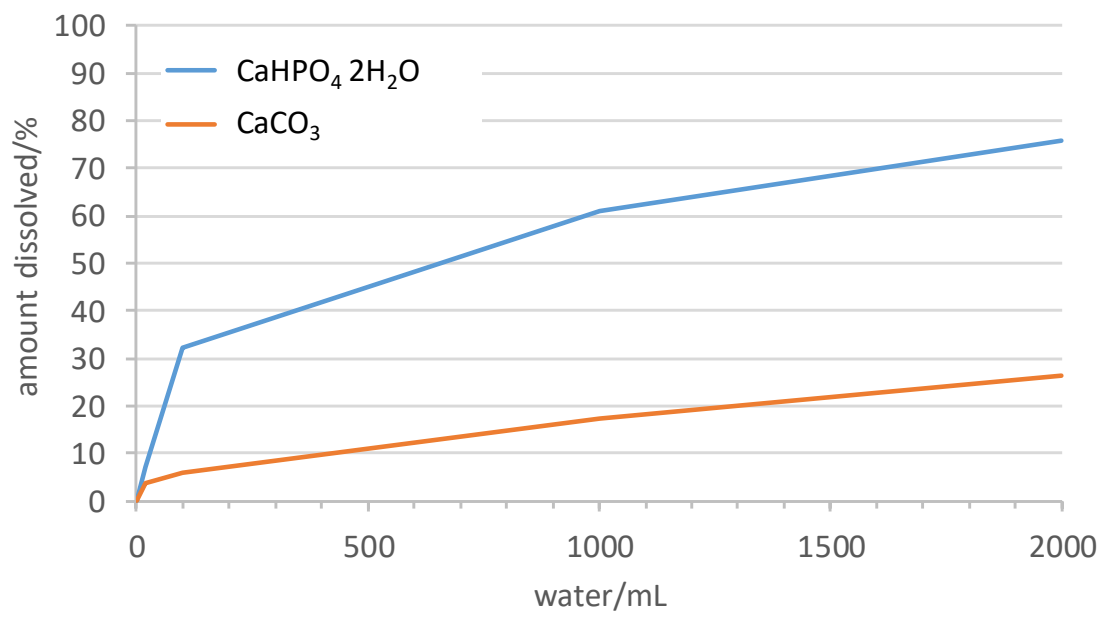


Figure S9. Impact scores for scenarios 1-3 and 7-9 in Table 3, expressed in \%, normalized internally to "No

phosphorus extraction" scenario, for which impacts are equal either $100 \%$ (for positive impact scores) or $-100 \%$ (for negative impact scores).

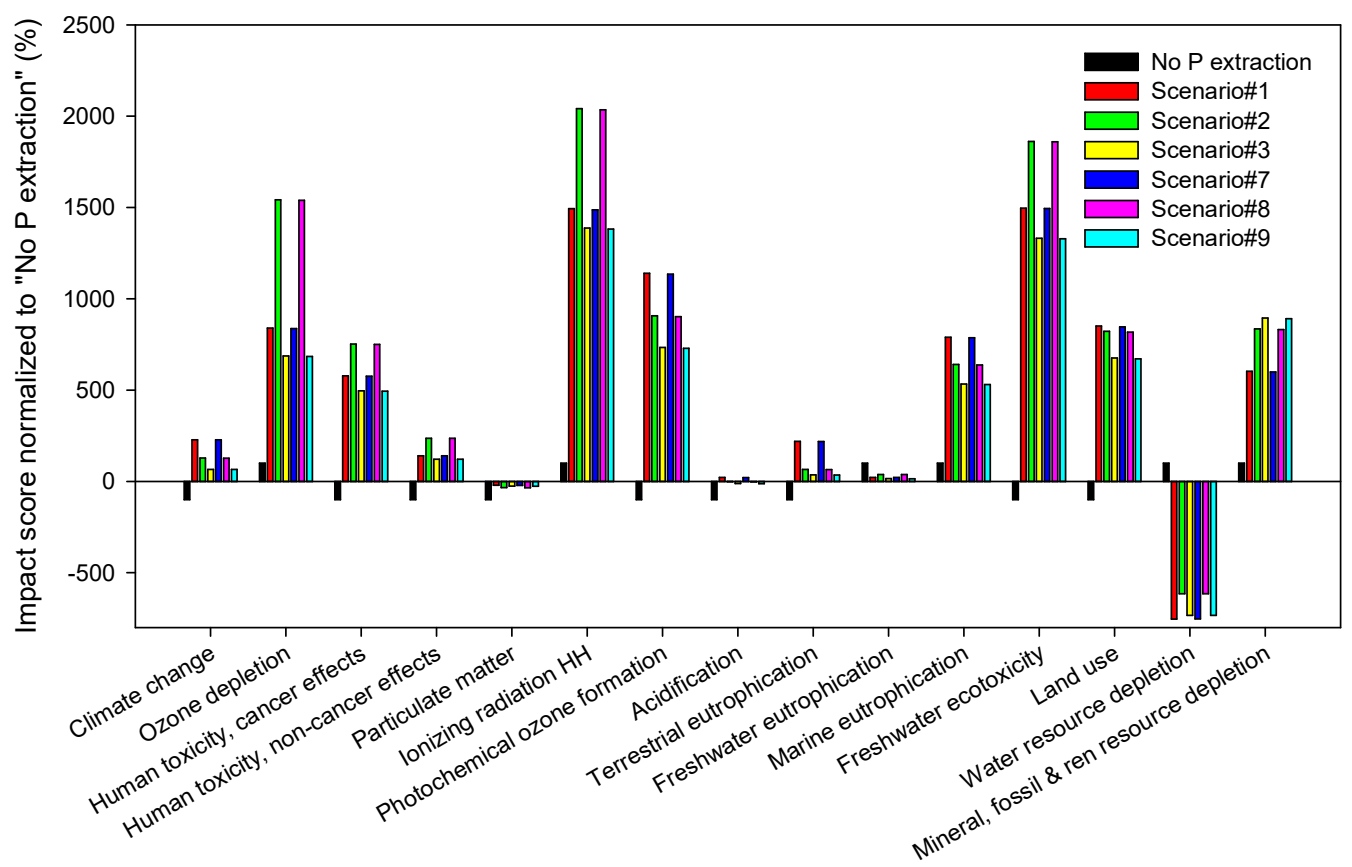

733

734

735

736

737

Figure S10. Impact scores for scenarios 1-3 and 10-12 in Table 3, expressed in \%, normalized internally to "No phosphorus extraction" scenario, for which impacts are equal either $100 \%$ (for positive impact scores) or $-100 \%$ (for negative impact scores).

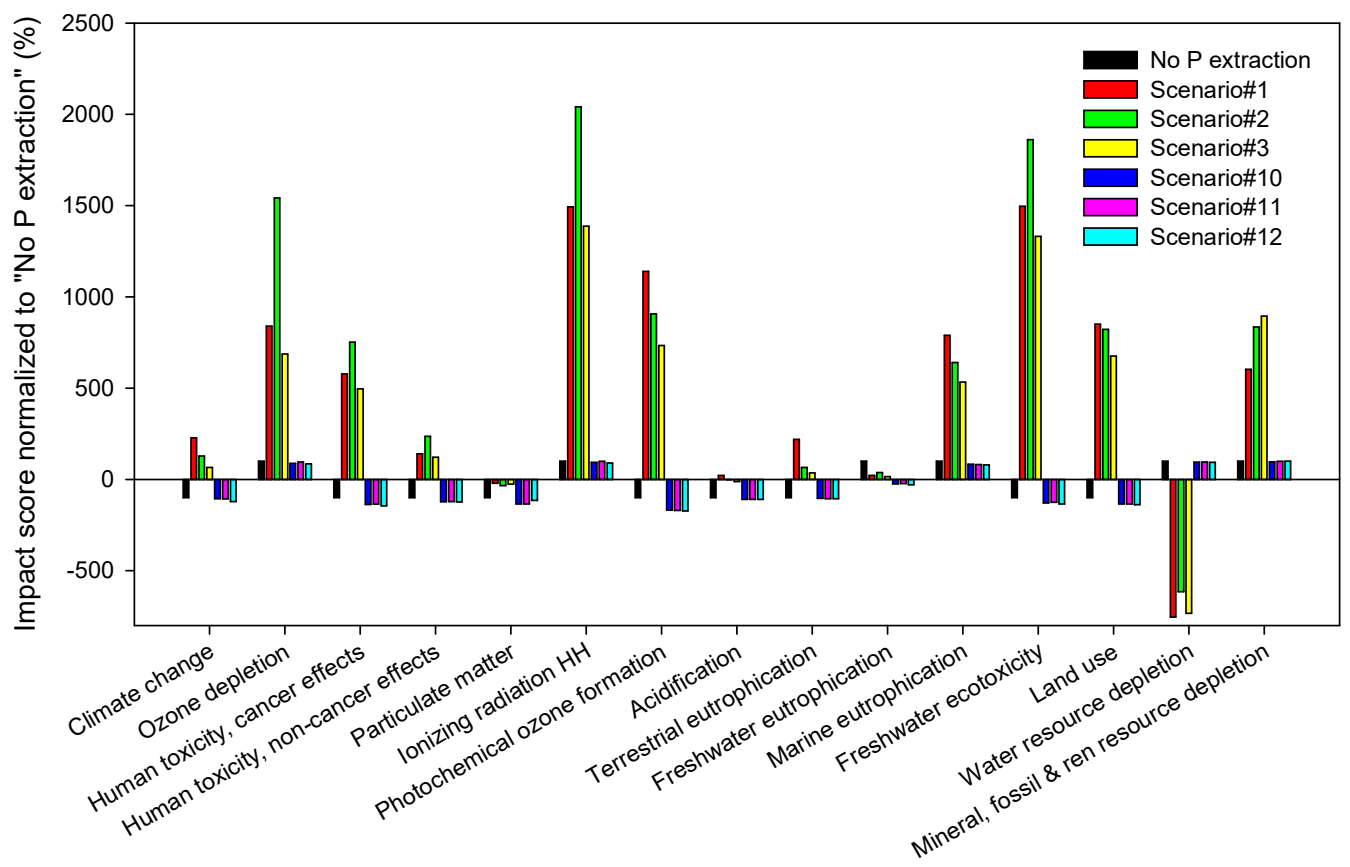

